\title{
Significant issues of legal regulaion of vehicle owners' civil liability insurance in Georgia
}

\begin{abstract}
The article deals with vehicle owners' civil liability insurance as the third party car insurance and social mechanism of security and highlights its significance under present conditions. On the basis of an analysis of the constitutional practices, it studies Georgian law on vehicle owners' civil liability insurance, whether it was expedient to abolish the previous law and anticipated results that would follow enactment of a new law and undoubtedly occur in case of introducing vehicle owners' civil liability insurance in respect of all motor vehicles, not limited to transit cars only. The article encompasses recommendations and modest suggestions. The work compiles the results of the research based on vehicle owners' awareness survey of the law on insurance and their attitudes towards it. It also concerns a shortage of financial education in Georgia, which hinders establishment of "Insurance Ethics".
\end{abstract}

Keywords: vehicles, civil, liability, compulsory, insurance, ethics, legal, regulation
Volume 2 Issue 5 - 2018

\author{
Zurab Mushkudiani,' Nana Shonia, ${ }^{2}$ Tamila \\ Khurtsidze, ${ }^{3}$ Darejan Saldadze ${ }^{3}$ \\ 'Department of Public Relation, Kutaisi City Council, Georgia \\ ${ }^{2}$ Department of Business Administration, Akaki Tsereteli State \\ University, Georgia \\ ${ }^{3}$ Department of law, Akaki Tsereteli State University, Georgia
}

Correspondence: Zurab Mushkudiani, Department of Public Relation, Kutaisi City Council, Kutaisi, Georgia, Email zara_8355@yahoo.com

Received: October 01, 2018 | Published: October 30, 2018

\section{Introduction}

Vehicle owners' civil liability insurance the share of which is quite high on the insurance market of developed countries, is just being introduced in Georgia. It is a guarantee not only for the affected third person to avoid undesirable consequences, but also for the contractor insurer. The insurance market is developing quite dynamically in Georgia, which is confirmed by the fact that particular emphasis has been placed on vehicle owners' civil liability insurance among the products of insurance companies. Considering that Georgia signed an Association Agreement with the EU in 2014 and insurance was determined as one of the most important issues of the financial area, the issue of harmonization of the legislative sphere of Georgia with the EU legislation is to be reconsidered in this regard. ${ }^{1-4}$ The law on compulsory vehicle insurance exists in 48 countries (the member states of the "Green Card" System) and regulates civil and legal relations resulting from traffic accidents which arise on the territory of a particular country during the movement and with the participation of all types of vehicles registered in a foreign country, causing damage to life, health and property of the third party. It is used as a means of protection - the mechanism of protection of the interests of vehicle owners during the implementation of insurance in case of damage. In Georgia the most urgent problem of vehicle owners' civil liability insurance is to decide whether it is necessary to make this form of insurance compulsory and whether it helps to maintain the financial security of the society by reducing the damages arising from the risks of liability. ${ }^{5-7}$ Another significant problem is to determine premiums and insurance limits in order not to impose the compulsory form of insurance on the society. It is necessary that compulsory insurance should ensure the expansion of the sphere of liability and reduce the frequency of risks in the future. The main hypothesis and objectives have been identified to solve these problems, which imply the study of the significant issues related to the compulsory insurance of vehicle owners' civil liability.

\section{Literature review}

Based on the aforementioned factors, the aim of the research was to study the advisability of the abolition of the previous law on "Compulsory Insurance of Vehicle Owners' Civil Liability" in Georgia and the anticipated consequences of the enactment of the new law. Neither the Law of Georgia on Insurance nor the Civil Code envisage vehicle insurance as a type of insurance. The service of vehicle owners' civil liability insurance has been available in Georgia only to vehicles entering the country since the Law on "Compulsory Insurance of Civil Liability of Owners of Vehicles Registered in a Foreign Country and Moving on the Territory of Georgia" came into force on March 1, 2018. Pursuant to Article 3 of the Law, "when a vehicle registered in a foreign country enters the territory of Georgia, the vehicle owners/drivers are obliged to insure their civil liability for the vehicle for the full term of their being on the territory of Georgia, but it shall not be less than the term defined by Article 5 of the law. ${ }^{9-11}$ The damage caused by the insurance case resulting from the participation of this vehicle or linked to it shall be compensated for through compulsory insurance."

In order to study the justification of the abolition of the previous law on compulsory vehicle insurance, based on the analysis of the constitutional practice, we discuss the advisability of the abolition of the previous Law on "Compulsory Insurance of Civil Liability of Vehicle Owners", ${ }^{12}$ the advantages of this law and issues related to it. We completely agree with Professor Besarion Zoidze on the matter that the invalidation of the law was undoubtedly a big mistake, since this law was a mechanism of protection of the interests of the participant of the civil turnover. ${ }^{13-16}$ By abolishing the law the participants of the turnover found themselves at a high risk, as it concerns the source of an immense threat and the likelihood of damages is high. The Constitutional Court of Georgia has given a significant explanation pertaining to this issue: The obligatory nature of insurance of this category is based on many circumstances worthy of consideration. Most importantly, the case involves civil liability insurance during which the damage is inflicted by an object which is the source of an immense threat and its owner carries more risks due to this characteristic. The traditional institute of property liability frequently fails to compensate for the damages caused by realization of the aforementioned threat. The introduction of the civil liability of vehicle owners makes it possible to distribute the liability in accordance to the interests of vehicle owners as well as affected 
persons. ${ }^{4,17}$ Due to the establishment of the compulsory insurance fund, damage compensation is not fully dependent on the property status of vehicle owners. Such insurance is based on the principle of universality and includes all owners of vehicles. Therefore, unlike voluntary insurance, it promotes the establishment of stable civil relations. During voluntary insurance the insurer might have faced a risk leading to a difficult situation. At the same time, if a person who caused the damage had poor property status, he or she would provide less guarantees for the effected person. Thus, compulsory insurance of the civil liability of vehicle owners makes it possible to socialize the insurance risk and distribute compensation among a wide circle of people carrying this risk by establishing an insurance fund.

The introduction of compulsory insurance for all types of vehicles on the territory of Georgia will undoubtedly lead to problems: if the previous law on "Compulsory Insurance of Civil Liability of Vehicle Owners" (abolished in 2010) implied compulsory insurance, the insurance premium was paid from the compulsory insurance fund, which was of great benefit to the insurer; these days, due to the current economic situation and unemployment, the introduction of this kind of compulsory insurance will definitely become a heavy burden for some vehicle owners, creating exploitative conditions for them, as confirmed by the research carried out in this regard. In accordance with the international standards, in the case of transit automobiles, insurance of drivers' civil liability to the third party is a great comfort to foreigners. The legislator is aimed at correcting the existing shortcoming, which is welcome but contradictory.

The decision of the Constitutional Court on contract coercion is particularly interesting in relation to the aforementioned issue, on the basis of the example of compulsory insurance (see Decision (N1/2/106) as of October 31, 2001 on the case-"The Citizens of Georgia - Irakli Beriashvili and Victor Inashvili v. The Parliament of Georgia"). The subject of the dispute was "The Law on Compulsory Insurance of Civil Liability of Vehicle Owners". The complainant claimed that the law violated the right to property provided for by Article 21 of the Constitution of Georgia, since it forced him to enter into a contract with an insurance organization and pay a certain sum of money. It was unclear to him why he was obliged to make a payment as he had not caused any "accident". Thus, the complainant raised two immensely serious issues before the court-contract coercion and the essence of the institute of insurance. The court responded to these questions in an interesting way, emphasizing that everything that takes place as provided for by the disputed law is in line with civil relations and the complainant had an illusion that contract coercion should not be included in private law. According to the decision, compulsory insurance of civil liability of vehicle owners might be deemed as one of the cases of legal restrictions on traditional obligatory relations.

\section{Methodological approach}

Data on vehicle owners' civil liability insurance was collected from Secondary sources like Articles, Journals, empirical literatures, Textbooks and Internet sources (peer-review data) for analysis on vehicle owners' civil liability insurance. Qualitative methodology was applied for this research paper. Descriptive research design and analysis on vehicle owners' civil liability insurance were employed to investigate the vehicle owners' civil liability insurance system. For the purpose of analysis, a secondary data was used to analyze the various literatures on vehicle owners' civil liability insurance. The researcher obtained both primary and secondary data from the various case studies for the analysis of the vehicle owners' civil liability insurance.
The primary data was in the form of interviews with concern officials for some organizations in Georgia.

\section{Conducting research and results}

The aim of this article is to examine the influence of the risks of the insurance of this type in order to study the anticipated results of the enactment of the new law on compulsory insurance of civil liability of vehicle owners. The analysis revealed that there is no full registration of traffic accidents in Georgia. In most cases participants of traffic accidents reach an agreement with regard to the outcomes of traffic accidents based on personal negotiations, without being supervised by authorized bodies or without informing them. Accordingly, the registered traffic accidents do not reflect even $50 \%$ of the real rates. Furthermore, public survey has shown that $80 \%$ of the population believes only $25-50 \%$ of the traffic accidents have been registered whereas approximately $50-75 \%$ remains unregistered, as confirmed by the results of the public survey conducted by us (Figure 1). The registration of the accidents in which insured vehicles are involved has been simplified. Since only 38674 vehicles (Kakheti Information Centre) out of 900000 vehicles have been insured in Georgia (Journal: Business Press News, 2017), i.e. 4-5\%, we can assume that $5 \%$ of the traffic accidents are undoubtedly registered. As for the uninsured vehicles, only rather serious cases of the traffic accidents caused by them are registered. Figure 2 shows registered traffic accidents in 2008-2016. The data have been compiled on the basis of the 2013, 2014, 2015 reports and the 2016 information data of the InformationAnalytical Department of the Ministry of Internal Affairs.

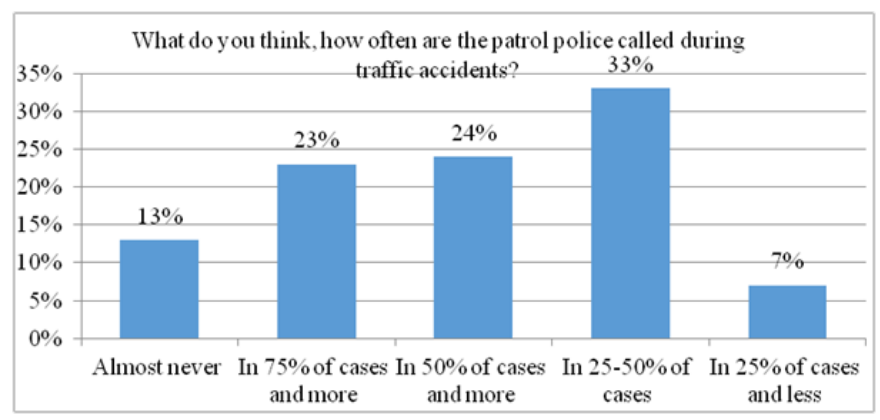

Figure I Results of public survey. Percentage of registered traffic accident cases in Georgia.

Source: Own results.

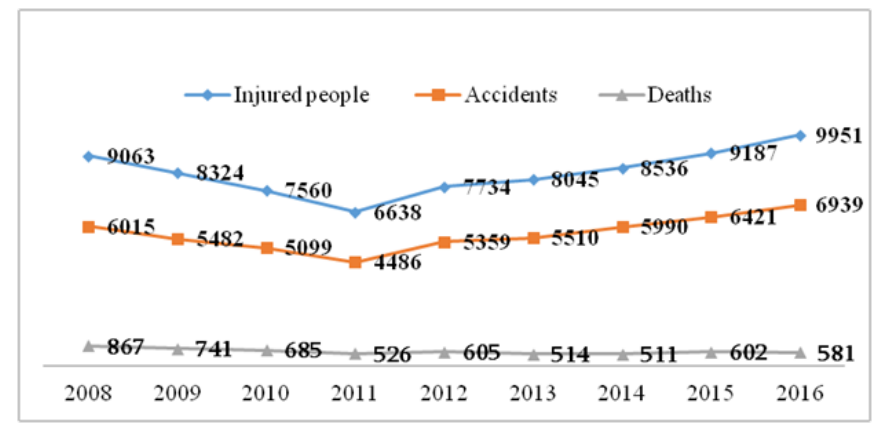

Figure 2 Dynamics of registered traffic accidents and their consequences in Georgia in 2008-2016

Source: (Information-analytical department of the ministry of internal affairs, 2013); (Information-analytical department of the ministry of internal affairs, 2014); (Information-analytical department of the ministry of internal affairs, 2015); (Samkhretis Karibche, 2016). 
Considering the opinion of the population, the registered traffic accidents constitute $25 \%$ of the total number of accidents. As for the frequency of traffic accidents, it is calculated based on the quotient of the number of accidents and registered vehicles (riskinstitute.org) and the frequency of traffic accidents which is calculated by dividing the number of traffic accidents by the number of registered vehicles (Information-Analytical Department of the Ministry of Internal Affairs, 2012); (Information-Analytical Department of the Ministry of Internal Affairs, 2016) is shown by Figure 3. As a traffic accident can be accompanied by body injuries, deaths and damages to property, it is necessary to compare the frequencies of general accidents and to carry out the analysis of the most significant factor - the death rate. There are relatively new data in Georgia in this regard. It should be noted that, along with the novelty of the data, this information is more accurate than the rates of the traffic accidents. The death of a person is recognized by the court as provided for by the Civil Code in Georgia as well as in European countries. Pursuant to the Law of Georgia on Civil Status Acts, Chapter VIII, within 5 days after death the medical certificate shall be submitted to the body of registration of civil status acts (Law of Georgia on Civil Status Acts No.5562). Consequently, registration of the deceased and identification of death causes provide accurate data. Table 1 illustrates the number of deaths in Georgia due to traffic accidents. The data have been compiled on the basis of the 2011, 2013 and 2014 reports of the Information-Analytical Department of the Ministry of Internal Affairs. Studies across Europe show the death rate per every one million people. Accordingly, the data provided by the Ministry of Internal Affairs have been revised per every one million people. In Georgia information about population is discussed based on the data of the Department of Statistics of Georgia.

Table I Death rate in Georgia per every one million people
Table 1 show that in 2016 there were 6939 registered traffic accidents in Georgia. As a result, 581 people died and 9951 were injured. Compared to the data of 2015, the number of traffic accidents increased by $7 \%$, the death rate decreased by $3 \%$ and the number of the injured people increased by $8 \%$. As for pedestrians, 154 of them died and 2159 were injured on the territory controlled by the patrol police in 2016. 59 pedestrians died and 1410 were injured in Tbilisi in 2015. In comparison to the data of 2015, the death rate of pedestrians increased by $4 \%$ and the number of the injured increased by $8 \%$ in Tbilisi in 2016, which indicates that the frequency of risks is increasing annually and its control is becoming even more important. In the course of the research it was considered advisable to study the level of public awareness of compulsory insurance of civil liability of vehicle owners. Figure 4 shows that $46 \%$ of the respondents are aware of the essence of MTPL compulsory insurance whereas 54\% do not understand the meaning of MTPL insurance, which confirms the information vacuum in this respect. The study of public attitude towards compulsory insurance has shown that $61 \%$ of the respondents accept the idea of the introduction of the compulsory form of MTPL insurance (Figure 5). The main reason for this is that most respondents perceive the frequency and severity of traffic accidents as a significant problem (Figure 6). The question is which part of the society in Georgia thinks it is necessary to introduce compulsory insurance? The results of the survey show that well-informed respondents suggest it is necessary to introduce this form of insurance whereas the respondents who believe insurance should not be compulsory are not aware of the essence of MTPL insurance. Figure 7 shows that out of $29 \%$ of the respondents who do not think MTPL insurance should be compulsory $25 \%$ do not understand the essence and meaning of compulsory MTPL insurance.

\begin{tabular}{|c|c|c|c|c|c|c|c|c|c|c|c|}
\hline Year & 2006 & 2007 & 2008 & 2009 & 2010 & 2011 & 2012 & 2013 & 2014 & 2015 & 2016 \\
\hline Deaths & 675 & 737 & 867 & 741 & 685 & 526 & 412 & 480 & 410 & 599 & 581 \\
\hline Population (million) & 4.4013 & 4.3947 & 4.3821 & 4.3854 & 4.4364 & 4.4692 & 4.4976 & 4.4838 & 4.49 & 3.713 & 3.718 \\
\hline $\begin{array}{l}\text { Death rate per every million } \\
\text { people }\end{array}$ & 153 & 168 & 198 & 169 & 154 & 118 & 92 & 107 & 91 & 161 & 156 \\
\hline
\end{tabular}

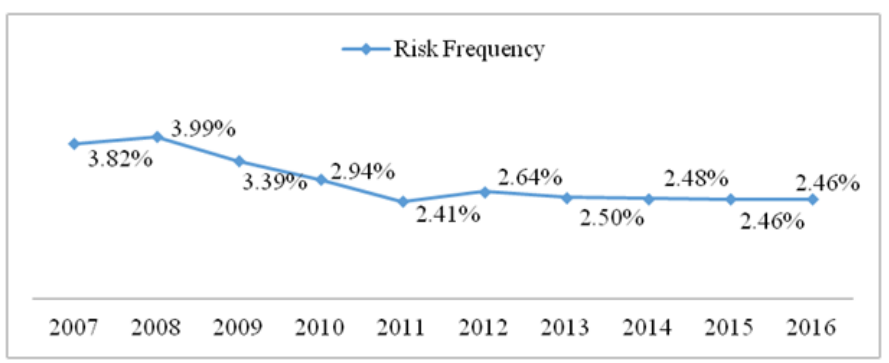

Figure 3 Frequencies of traffic accidents in Georgia in 2007-2016.

Source: Own results.

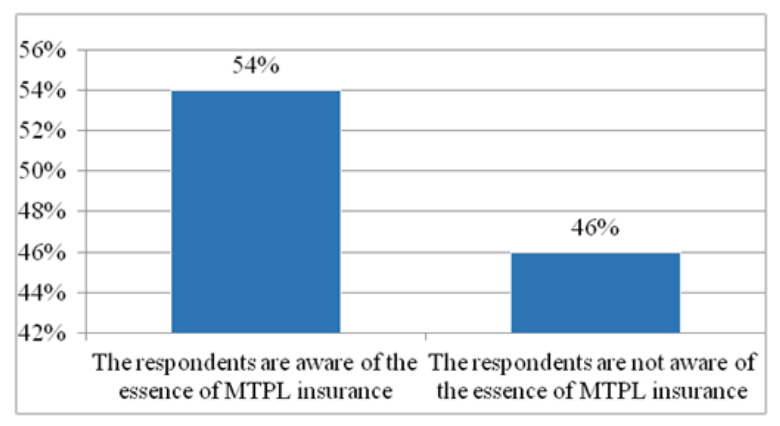

Figure 4 Level of respondent awareness of MTPL compulsory insurance.

Source: Own results. 


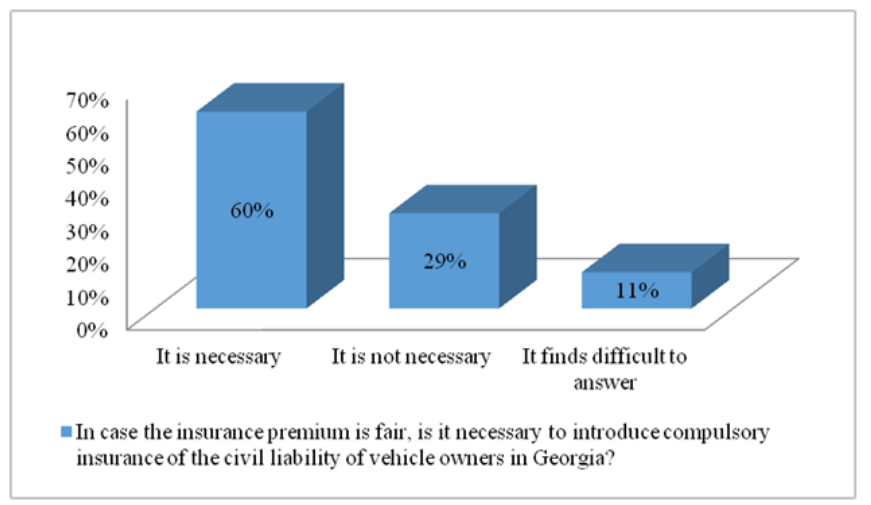

Figure 5 Public attitudes towards compulsory insurance.

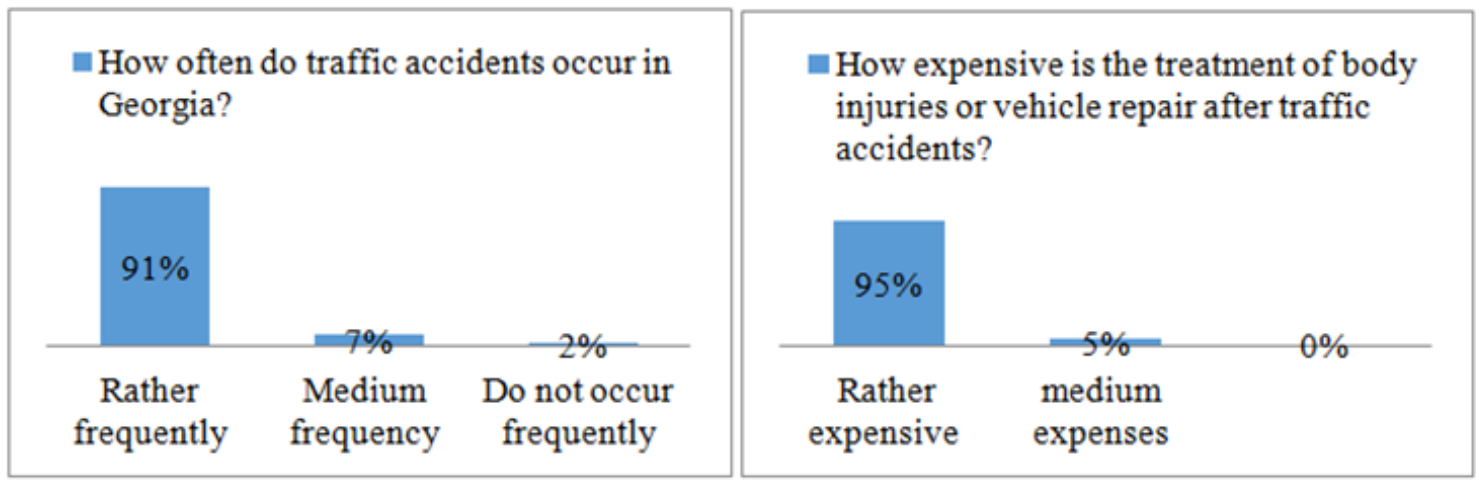

Figure 6 Evaluation of frequency and severity of traffic accidents by public (Respondents).

Source: Own results.

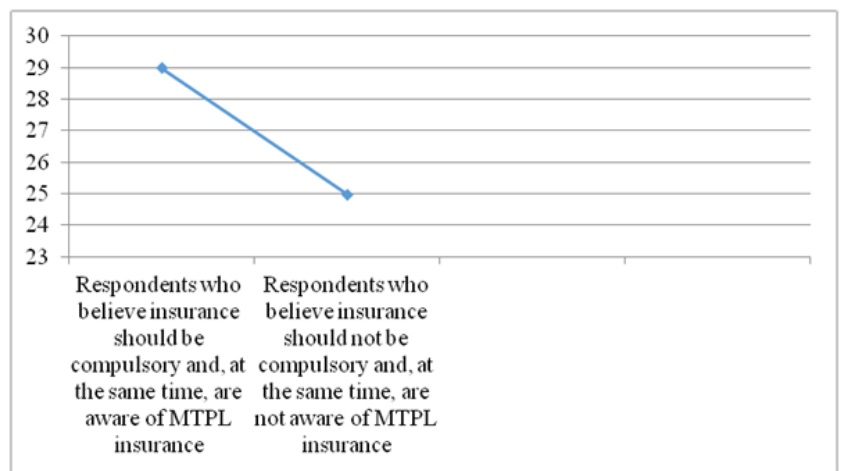

Figure 7 Respondents who believe insurance should/should not be compulsory and, at the same time, are/are not aware of MTPL insurance.

\section{Source: Own results.}

\section{Conclusion}

The purpose of this study is to address the increase in the share of insurance of the civil liability of vehicle owners in overall insurance depends on the growth of economy, on an inflow of foreign investment, and, generally, on the development of industry. Moreover, current situation in Georgia reveals the reason for the lack of this type of insurance. How with the growth of the economy the demand for the product of this type of insurance will increase. Based on this analysis of the constitutional practice, the necessity of introducing compulsory insurance of the civil liability of vehicle owners has become obvious. However, the research has revealed the anticipated contradictions which may result from the enactment of the law on compulsory vehicle insurance. Despite the results of complex research carried out in relation to compulsory vehicle insurance and the public attitude, we, as scientists, believe it is necessary to introduce the law on compulsory insurance of the civil liability of vehicle owners not only for transit cars but also for all types of vehicles. It will be advisable to take into account the specifics of the financial condition of the population and regulations when adopting the law. It is especially important to consider the fact that pursuant to the previous law on "Compulsory Insurance of Civil Liability of Vehicle Owners" the insurance premium was paid from the compulsory insurance fund, which was of great benefit to the insurer; these days, due to the current economic situation and unemployment, the introduction of this kind of compulsory insurance will definitely become a heavy burden for some vehicle owners, which has been confirmed by the research results, as mentioned above. Thus, compulsory insurance of the civil liability of vehicle owners is a mechanism which, in addition to creating a flexible system of social security and ensuring the guarantees for compensation for damages, will contribute to the resolution of disputes and solution of problems arising from traffic accidents in a civilized way. The country will have an opportunity to join the 48 states - the members of the international insurance - the"Green Card"System, will promote tourism development, and most importantly, will ensure the harmonization of the Georgian legislation with the EU legislation. 


\section{Acknowledgements}

None.

\section{Conflict of interest}

The author declares that there is no conflict of interest.

\section{References}

1. Baram MS. International workshop on liability and insurance and their influence on safety management of industrial operations and products. Journal of Risk Research. 2014;17(6):683-687.

2. Ben Shahar O, Logue K. Outsourcing regulation: How insurance reduces moral hazard. Chicago: Institute for law and economics working paper. University of Chicago Law School. 2012;111(2):593.

3. Bentata P. On the joint use of safety regulation and civil liability to promote safe management of hazardous operations: A French case study. Journal of Risk Research. 2014;17(6):721-734.

4. Clarke M. Policies and Perceptions of Insurance Law in the Twenty-First Century. UK: Oxford University Press. 2007. 374 p.

5. Akhvlediani Z. Obligatory Law. Tbilisi, Georgia: Publishing House; 2012. $25 \mathrm{p}$

6. Gvaramia L. Legal basis for the use of civil liability insurance. Georgia: Oxford press; 2014. $17 \mathrm{p}$.

7. Makharadze N. Subjects of Insurance Contract and their Legal Status. Tbilisi, Georgia; 2015.
8. Law on Compulsory Insurance of Civil Liability of Owners of Vehicles Registered in a Foreign Country, Moving on the Territory of Georgia. 2017.

9. Tsiskadze M. Obligatory insurance of civilian liability of auto owners. Georgia. 2016.

10. Vashakidze G. System of complicated liabilities of the Civil Code. Georgia; 2015.

11. Marchant GE. 'Soft Law' mechanisms for nanotechnology: liability and insurance drivers. Journal of Risk Research. 2014;17(6):709-719.

12. Law on Determining the Amount of Insurance Money While Implementing Compulsory Insurance of Civil Liability of Vehicle Owners. Georgia. 2003 .

13. Zoidze B. Constitutional Control and Order of Values in Georgia. Georgia: Oxford University; 2015. 59 p.

14. Merkin D. Insurance and The Law of Obligation. UK: Oxford University Press; 2013. 414 p.

15. Lowry J. Insurance Law: Doctrines and Principles. USA: Hart Publishing; 2011. 618 p.

16. Cruze P De. Comparative Law in a Changing World. USA: Abingdon, Oxfordshire; 2016. 532 p.

17. Jerry RH, Douglas RR. Understanding Insurance Law. USA: Carolina Academic Press; 2012. 1152 p. 